\title{
Effects of semantic list structure differences in free recall*
}

\author{
JAMES W. PELLEGRINO and WILLIAM F. BATTIG \\ Institute for the Study of Intellectual Behavior \\ University of Colorado, Boulder, Colo. 80302
}

Free recall learning of a mixed list of 20 related and 20 unrelated words was enhanced more if the related words belonged to common taxonomic categories than if they were hierarchically ordered as a single branch of a "semantic tree" (e.g., animal, mammal, dog, terrier). The same difference obtained in 1-week delayed recall. No significant taxonomic-hierarchic differences were found in clustering. More detailed analyses indicated the hierarchical recall decrement to reflect fewer recalled items per set during learning, but fewer sets represented in delayed recall. These results were interpreted on the basis of a two-stage retrieval process, distinguishing access to a semantic set from subsequent access to items within the set.

Current theories of human memory have proposed that the probability of recall for an item or a set of items is a function of the various semantic and orthographic attributes involved in the original encoding (e.g., Bower, 1967; Kintsch, 1970; Underwood, 1969). In the free recall paradigm, the two most common semantic relationships that have been investigated are taxonomic category membership and hierarchic category structure. The major difference between the two is that typical taxonomic category sets represent only one level of a larger hierarchic structure.

Investigations of semantic hierarchies (e.g., Bower, Clark, Lesgold, \& Winzenz, 1969) have been limited to large tree structures such that overall hierarchic structure as well as taxonomic category membership are present simultaneously. Thus, no comparison has yet been provided between typical taxonomic sets and hierarchic sets containing only the hierarchic property of specific directionality. It is possible, however, to construct such sets by selecting one branch of a larger tree, e.g., animal-mammal-dog-terrier.

This experiment attempted to compare performance on these two different types of semantic relationships wherein the number of words within each of the sets would be equal and the differences in semantic structure would reflect horizontal vs vertical relationships with respect to a larger semantic tree. Two different types of hierarchic sets were used,

${ }^{*}$ This paper is a publication of the Institute for the Study of Intellectual Behavior, University of Colorado. The research reported herein was supported by National Science Foundation Grant GB-25433 to the second author and by USPHS Fellowship MS 8030-0151 held by the first author from the National Institute of Mental Health. The authors gratefully acknowledge the assistance of Colleen Tovani in tabulating the data. denoting type-of and part-of relationships (Kintsch, 1970). It was hypothesized that hierarchic when compared to taxonomic word sets would show less recall and organization under randomized list order conditions. The assumption was that specific directionality is important for perceiving the semantic relationship present within the hierarchic sets and that any separation or disruption of the appropriate order would reduce $S$ 's ability to perceive and use this relationship as an aid to recall and as a means of organizing individual words into units.

\section{DESIGN AND MATERIALS}

The design was a 2 by 2 by 3 mixed factorial, manipulating experimental group (taxonomic vs hierarchic), word relatedness (related vs unrelated), and point of recall test (Trials 1 and 2 and 1 -week delay). There were two groups of Ss, with each group viewing a 40 -item randomized list containing 20 related and 20 unrelated words. In both groups, the related words consisted of five sets with four words/set differing only in the type of semantic relationship exemplified in each set, while the 20 unrelated words were identical in both groups. All taxonomic category members were high in taxonomic frequency for their respective categories (Battig \&

Table 1

Means and SDs for Recall as a Function of Experimental Condition, Word Relatedness, and Point of Recall Test

\begin{tabular}{|c|c|c|c|c|c|c|}
\hline \multirow[b]{2}{*}{ Word Sets } & \multirow{2}{*}{$\begin{array}{c}\text { Experimental } \\
\text { Conditions }\end{array}$} & & \multicolumn{2}{|c|}{ Recall Test } & \multirow[b]{2}{*}{ Delay } & \multirow[b]{2}{*}{$\overline{\mathbf{X}}$} \\
\hline & & & Trial 1 & Trial 2 & & \\
\hline \multirow{2}{*}{ Related } & Taxonomic & $\begin{array}{l}\text { Mean } \\
\text { SD }\end{array}$ & $\begin{array}{l}9.81 \\
3.46\end{array}$ & $\begin{array}{r}15.27 \\
2.92\end{array}$ & $\begin{array}{r}10.38 \\
3.22\end{array}$ & 11.82 \\
\hline & Hierarchic & $\begin{array}{l}\text { Mean } \\
\text { SD }\end{array}$ & $\begin{array}{l}7.03 \\
2.43\end{array}$ & $\begin{array}{r}12.70 \\
2.96\end{array}$ & $\begin{array}{l}7.95 \\
4.06\end{array}$ & 9.23 \\
\hline \multirow{2}{*}{ Unrelated } & Taxonomic & $\begin{array}{l}\text { Mean } \\
\text { SD }\end{array}$ & $\begin{array}{l}5.78 \\
1.95\end{array}$ & $\begin{array}{r}10.87 \\
2.57\end{array}$ & $\begin{array}{l}6.41 \\
3.11\end{array}$ & 7.69 \\
\hline & Hierarchic & $\begin{array}{l}\text { Mean } \\
\text { SD }\end{array}$ & $\begin{array}{l}6.57 \\
1.99\end{array}$ & $\begin{array}{r}10.43 \\
2.52\end{array}$ & $\begin{array}{l}6.27 \\
2.63\end{array}$ & 7.76 \\
\hline
\end{tabular}

Montague, 1969), but lower in word frequency than the hierarchic words. SUBJECTS AND PROCEDURE

The $37 \mathrm{Ss}$ in each group were University of Colorado students participating in an undergraduate statistics class, with all Ss tested simultaneously. Several additional students in the class were eliminated as Ss because they had previously served in another experiment using these words. The list materials were projected individually on the classroom walls at a 3 -sec rate by means of separate Kodak Carousel projectors for each group, arranged so that each $S$ could see only the appropriate set of materials. The Ss were given two standard free recall trials, with approximately $3 \mathrm{~min}$ for recall on each trial, followed by a 1-week delayed recall test.

\section{RESULTS \\ Recall}

The overall recall results are presented in Table 1. There was a significant superiority of taxonomic over hierarchic groups, $F(1,72)=6.74$, which was due entirely to the related words, $F(1,72)=25.19$. The superiority of related over unrelated word sets was highly significant, $F(1,72)=111.24$. Differences between successive recall tests, $F(2,144)=$ 271.66 , as well as its interaction with related-unrelated words, $F(2,144)=$ 3.05 , were also significant.

To determine the exact locus of the related word differences between groups, analyses were also performed on mean percentage of semantic sets and items per set recalled, shown in Table 2. In the analysis of percent semantic sets, taxonomic were significantly superior to hierarchic Ss, $F(1,72)=8.60$, and recall tests differed significantly, $\mathbf{F}(2,144)=$ 41.80 , with a significant interaction between these two variables, $F(2,144)$ $=3.22$. The analysis of percent items per set also showed a significant difference between groups, $F(1,72)=$ 16.84, and a significant recall test effect, $F(2,144)=30.30$, but a nonsignificant interaction opposite in direction to that observed for percent 
Table 2

Mean Percent Semantic Sets and Items Per Set Recalled as a Function of Experimental Condition and Point of Recall Test

\begin{tabular}{|c|c|c|c|c|c|}
\hline \multirow{2}{*}{$\begin{array}{l}\text { Recall } \\
\text { Measure }\end{array}$} & \multirow{2}{*}{$\begin{array}{l}\text { Experimental } \\
\text { Conditions }\end{array}$} & \multirow[b]{2}{*}{ Trial 1} & \multicolumn{2}{|c|}{ Recall Test } & \multirow[b]{2}{*}{$\overline{\mathbf{X}}$} \\
\hline & & & Trial 2 & Delay & \\
\hline \multirow{3}{*}{$\begin{array}{l}\text { Percent Semantic } \\
\text { Sets Recalled }\end{array}$} & Taxonomic & 81 & 97 & 82 & 87 \\
\hline & Hierarchic & 76 & 94 & 67 & 79 \\
\hline & Difference & 5 & 3 & 15 & \\
\hline \multirow{3}{*}{$\begin{array}{l}\text { Percent Items Per } \\
\text { Sets Recalled }\end{array}$} & Taxonomic & 60 & 77 & 63 & 67 \\
\hline & Hierarchic & 47 & 68 & 60 & 58 \\
\hline & Difference & 13 & 9 & 3 & \\
\hline
\end{tabular}

semantic sets, $F(2,144)=2.17$, $\mathrm{p}>.05$.

\section{Organization}

Clustering. ARC clustering scores (Roenker, Thompson, \& Brown, 1971) were obtained for all Ss, providing a measure of the relative amount of clustering produced for the related words that were recalled. These data are summarized in Table 3 . There was no significant difference between groups $(p>10)$, and nor was there an interaction between this variable and point of recall test $(F<1)$. The only significant effect was the overall difference between successive recall tests, $F(2,144)=13.43$.

\section{Primacy-Recency}

Those items comprising the first and last eight presentation order positions on each trial were examined with respect to relative position in the recall order on both trials, using the standardized recall rank techniques (Pellegrino \& Battig, in press). Positive and negative values, respectively, indicate recall before or after the median. The mean rank values are as shown in Table 4. Only the trials difference, $F(1,72)=11.90$, and the interaction between trials and the primacy-recency variable, $F(1,72)=$ 9.90 , reached significance, reflecting the reversed and smaller primacy-recency difference from Trial 1 to Trial 2 evident in Table 4 .

$$
\text { DISCUSSION }
$$

The overall recall results support that part of the initial hypothesis predicting poorer performance on the hierarchic related word sets, with this effect occurring even after a 1-week delay. They are also in general agreement with previous data showing
Instead, certain members of the hierarchic sets may not have been encoded according to the semantic structure, especially those occurring early in the presentation sequence. However, after the $S$ had one exposure and test, the second-stage decrement was reduced and disappeared in the delayed test.

The taxonomic-hierarchic difference in the delayed test was due entirely to the first stage of retrieval, i.e., the ability to gain access to all the different semantic sets in the list. Thus, over the delay interval, the hierarchic group seems to have lost the general semantic cues or labels for all the sets. This interpretation seems consistent with the absence of simple salient labels for the hierarchic sets like those for taxonomic category sets. This interpretation was further supported by analyses indicating that over the delay interval, the probability of losing all the items previously recalled in a set was twice as high in the hierarchic as in the taxonomic group.

Another important consideration in the present results is that, while recall decreased from Trial 2 to delay test, the relative amount of organization increased, similar to an effect observed by Cofer (1967) for 5-min delay intervals. The present result probably reflects the domination of the first few trials of a free recall task by organizational factors other than semantic structure, as previously shown by Pellegrino \& Battig (in press). It is clear that the semantic relationships are perceived, since $S$ can demonstrate high levels of semantically based organization after a week's delay. However, the temporal factors of the recall situation, i.e., presentation order effects, are very important determinants of recall order early in learning, as indicated by the present primacy-recency data. When such factors are largely eliminated, as in the delayed test, the semantic relationships predominate. The present primacy-recency data also support previous data (Pellegrino \& Battig, in press) demonstrating the reversal in these processes from Trial 1 to Trial 2 in typical free recall as well as their
Table 3

Means and SDs of ARC Clustering Scores as a Function of Experimental Condition and Point of Recall Test

\begin{tabular}{llcccc}
\hline $\begin{array}{l}\text { Experimental } \\
\text { Conditions }\end{array}$ & & \multicolumn{4}{c}{ Recall Test } \\
\hline \multirow{2}{*}{ Taxonomic } & Mean & Trial 1 & Trial 2 & Delay & $\bar{X}$ \\
& SD & .47 & .65 & .69 & .60 \\
Hierarchic & Mean & .39 & .23 & .28 & \\
& SD & .39 & .53 & .69 & .53 \\
& & .43 & .28 & .38 & \\
\hline
\end{tabular}

Table 4

Means and SDs of Standardized Recall Rank $V$ alues for Primacy and Recency Components of List as a Function of Experimental Condition and Trial

\begin{tabular}{lllllll}
\hline & & \multicolumn{2}{c}{ Trial 1 } & & \multicolumn{2}{c}{ Trial 2 } \\
$\begin{array}{l}\text { Experimental } \\
\text { Conditions }\end{array}$ & & Prim & Recen & Prim & Recen \\
\hline \multirow{2}{*}{ Taxonomic } & Mean & .14 & .06 & .02 & .04 \\
& SD & .08 & .06 & .03 & .04 \\
Hierarchic & Mean & .22 & .04 & -.02 & .10 \\
& SD & .12 & .06 & .05 & .04 \\
\hline
\end{tabular}


general usage early in learning. The role of such factors in determining recall order early in learning is also related to the present absence of a constant "some or none" items per set function (Cohen, 1966). The present changes in this function indicate that a some-or-none relationship may hold only on later trials when semantic rather than serial or temporal factors are the primary determiners of recall order.

In summary, the results of this experiment indicate that recall differences between various semantically related sets of items can be a function of either or both of two general retrieval processes. Additionally, it was demonstrated that initial free recall performance may be dominated by factors other than semantic relationships such tnat the ability to subsequently use such relationships as recall cues may be seriously underestimated.

\section{REFERENCES}

BATTIG, W. F., \& MONTAGUE, W. E. Category norms for verbal items in 56 categories: A replication and extension of the Connecticut category norms. Journal of Experimental Psychology Monograph, 1969,80 , No. 3, Part 2.

BOWER, G. A multicomponent theory of the memory trace. In $K$. W. Spence and J. T. Spence (Eds.). The psychology of learning and motivation. Vol. 1. New York: Academic Press, 1967. BOWER, BOWER, G., CLARK, M., LESG OLD, A., \& WINZENZ, D. Hierarchical retrieval schemes in recall of categorized word lists. Journal of Verbal Learning \& Verbal Behavior, 1969, 8, 323-343.

COFER, C. N. Does conceptual organization influence the amount retained in immediate free recall. In B. Kleinmutz (Ed.), Concepts and the structure of memory. New York: Wiley, 1967.

COHEN, B. H. Some-or-none characteristics of coding behavior. Journal of Verbal Learning \& Verbal Behavior, 1966, 5. 182-187.

KINTSCH, W. Models for free recall and recognition. In D. A. Norman (Ed.), Models of human memory. New York: Academic Press, 1970.

PELLEGRINO, J. W., \& BATTIG, W. F. Relationships among higher order organization measures and free recall. Journal of Verbal Learning \& Verbal Behavior, in press.

PUFF, C. R. An investigation of two forms of organization in free recall. Journal of Verbal Learning \& Verbal Behavior, $1970,9,720-724$.

ROENKER, D. L., THOMPSON, C. P., \& BROWN, S. C. A comparison of measures for the estimation of clustering in free recall. Psychological Bulletin, 1971, 76, 45-48.

UNDERWOOD, B. J. Attributes of memory. Psychological Review, 1969, 76, 559-573. 